\title{
Demonstrable Disability
}

\begin{abstract}
This essay is about how disability rhetoric functions in early modern plays beyond the visible difference of disabled characters. In a medium that makes meaning out of bodies, disability rhetoric registers how much the language of disqualification can only succeed without the human form of the actor. Disability epithets define other bodies on the stage as whole and unmarked by negation, or, by contrast, have the effect of unsettling the scrutiny of the bodies that are onstage. Attention to disability rhetoric thus offers an instructive study because it succinctly outlines the concepts that ossify into, and serve to naturalize, negative images of early modern disability.
\end{abstract}

This essay considers how disability rhetoric functions in early modern plays beyond the visible difference of disabled characters. First: an illustrative experiment. If you turn to an online database of early modern drama - say, for example, a research tool such as the Open Source Shakespeare concordance - and enter a keyword associated with bodily difference, one of many terms we might consider an early modern analogue for our contemporary vocabulary of disability, the results are surprising. A search of 'lame' returns eighteen instances across Shakespeare's corpus, and only rarely do these phrases discursively construct a character's body in the present. ${ }^{1}$ In As You Like It, for example, 'lame' is a future that Adam imagines for his 'old limbs' (2.3.685); 'lame' is Rosalind's critique of poetic feet in verses that 'could not bear themselves' (3.2.1279); and 'lame' is Celia's verb of choice for the effect of an onslaught of words (1.3.412). The term evokes bodily limitation, but it works abstractly rather than describing a character's body or becoming a cue to an actor's practice. Similar patterns emerge in examples from other plays by Shakespeare. When Aufidius realizes he would 'lame the foot / Of our design' (Coriolanus 4.7.3224-5) and Desdemona laments 'O most lame and impotent conclusion' (Othello 2.1.949), the metaphor takes for granted a powerful analogy between bodies that can function and other objects that receive praise

Katherine Schaap Williams (ks.williams@utoronto.ca) is an assistant professor in the department of English at the University of Toronto. 
when whole and complete (design, reason, a good poem). They do not, however, describe a body on the stage.

A second search for another term closely associated with discussions of early modern disability takes this problem of the vexed relation between discursive term and embodied form even further. Critics have tended to read 'monstrous' as a signifier for extreme bodily difference, a conceptual analogue for bodies that would today be identified in terms of congenital deformity. ${ }^{2}$ Unlike 'lame' the term was not adduced in a legal category that governed the cultural administration of disability in the early modern period but appears in natural-philosophical, political, and theological contexts that employ 'monstrous' to describe extraordinary bodily variance. ${ }^{3}$ With the exception of Caliban's persistent description as 'monster', however, 'monstrous' in Shakespeare's works rarely describes the physical appearance of a character in the sixty-five times it appears. In phrases like 'monstrous devices' (1 Henry IV 2.4.1298), 'monstrous malefactor' (Antony and Cleopatra 2.5.1116), 'monstrous lust' (Pericles 5.3.2623), 'monstrous arrogance' (Taming of the Shrew 4.3.2070), and 'monstrous villainy' (Titus Andronicus 4.4.2063), the adjective is a register of disproportioning excess, the magnification of a pre-existing problem. ${ }^{4}$ Most often, though, the term is an exclamation that does not specify an object as much as enact a speaker's responsive horror: 'O monstrous!' (Titus Andronicus 1.1.348; 2 Henry VI 4.2.2390), 'O monstrous! monstrous!' (Othello 3.3.2109), and 'Most monstrous!' (King Lear 5.3.3313). These exclamations take advantage of the theatre's act of showing — to gesture to the root word 'monster', meaning 'to show' or 'to warn' - to recast an event, sight, or thought not because of physical monstrosity but rather as a metaphor.

The results of such keyword searches far outstrip a single character or specific embodiment. Given the emphasis on embodied representation in recent critical work in early modern disability studies, it may seem counter-intuitive to ask that we take these brief examples of single keywords seriously. Yet I suggest they gesture to a difficulty in how literary scholars render disability legible in the past. Foundational work in disability studies and subsequent reiterations in early modern disability studies have long taken Shakespeare's Richard III, and its emphasis on the appearance of its titular character, as the paradigmatic example of disability. Recent critical work has more generally stressed the prevalence of theatrical representation in accounts of disability in the period. I have argued elsewhere that the actor's embodiment fundamentally changes how we understand disability because we must account for the body of the actor. ${ }^{5}$ Lindsey Row-Heyveld finds that dramatic representations 'played a vital role in both shaping literary fantasies about the non-standard body and creating social realities for people with 
disabilities'. ${ }^{6}$ And Genevieve Love connects the prevalence of disability metaphors in bibliographical language about early modern play-texts (characterizing them as 'maimed' or 'deformed', for example) to figures of disability in plays, showing how language is 'intimately bound to those original, embodied figures'? Yet when we consider how frequently disability rhetoric appears in early modern drama, such an array produces the vertiginous sense that confining our attention to a character's theatrical embodiment actually narrows the premises of how we think about disability.

I intend this keyword exercise not as a methodological intervention but as a provocation, one that asks us to take stock of the curious tendency of disability rhetoric on the early modern stage not to describe bodies of actual characters. Such terms more frequently seem to index a free-floating set of social attitudes. (In this regard the early modern period is perhaps not so different from our present moment. Despite efforts to expand awareness about rhetoric and inclusion, and much perceptive scholarship on the prevalence of disability metaphors, our students and colleagues casually employ epithets such as 'lame', 'blind', or 'idiotic' as metaphors with distressing regularity.) Such metaphorical uses of disability escape 'narrative prosthesis' in the sense that David T. Mitchell and Sharon L. Snyder have taught us to understand disability metaphors as standing for the disabled person; floating free of a character, the rhetorical uses of these terms do not easily map onto narrative and plot. ${ }^{8}$ Studies of disability rhetoric by James Berger and Jay Dolmage have offered valuable accounts of rhetoric's essential root in the body and of the rhetorical functions of disability in relation to speaking bodies. ${ }^{9}$ Yet the lack of characters from which and about which this rhetoric issues troubles the relay between representation and description, complicating too the ambition that Allison P. Hobgood and David Houston Wood describe as 'ethical beholding' when they envision returning to Renaissance texts and their depictions of people with disabilities. ${ }^{10}$ The question these examples pose is something like, what happens when disability rhetoric flourishes without a body to anchor the ideas about embodiment such rhetoric encodes?

To take up this question, I draw on Michael Bérubé's recent study of disability and narrative function, in which he suggests that 'disability in the relation between text and reader need not involve any character with disabilities at all'. In Bérubé's formalist analysis, the field of disability studies is 'not confined to the representation of human bodies and minds in literary texts' because 'disability is also, always already, a social relation, involving beliefs and social practices that structure the apprehension of disability — and of putative human "norms". ${ }^{11}$ Disability representations demand that we consider the web of human relations 
and social structures that frame how difference matters. This essay takes up two examples in which disability rhetoric is amplified, even to the point of producing dramatic character. These examples ask us to think about something like disability without bodies by showing us how disability rhetoric accretes to a form that is not there and, in the process, exposes social relations in the play. To be sure, such examples draw on a forceful reserve of cultural ableism: the invocations of disability that follow are resolutely negative. Yet this rhetorical use also departs from affective scenes of pity, disgust, or humour directed at disabled characters. Precisely because such a figure never appears but is invoked, the denotation of disability operates without the embodiment of a character. In a theatrical medium that makes meaning out of bodies, disability rhetoric registers how much the language of disqualification can only succeed without the human form of the actor. In some instances, disability rhetoric works to define by negation other bodies on the stage as whole and unmarked or, by contrast, has the effect of unsettling the scrutiny of the bodies that are onstage. Attention to disability rhetoric thus offers an instructive study in the moments this language is not directed at a character because it succinctly outlines the concepts that ossify into - and serve to naturalize — negative images of early modern disability.

\section{If/Then}

At the centre of William Shakespeare's King John is a litany of bodily difference. Earlier in the play (and throughout), physical resemblance is repeatedly summoned as legitimating evidence of a claim to inheritance. These claims work horizontally, as sibling resemblance ('Look here upon thy brother Geoffrey's face: / These eyes, these brows, were moulded out of his. / This little abstract doth contain that large' [2.1.99-101]), and vertically, as patriarchal inheritance ('Liker in feature to his father Geoffrey / Than thou and John' [126-7]), and Constance posits them. ${ }^{12}$ She is the character who most forcefully insists that appearance offers a kind of certainty, that resemblance can anchor a set of social claims about identity and organize familiar bonds. The play reproduces this theme of resemblance in the subplot of Philip the Bastard, when questions of appearance expose the claim to inheritance of family lands. Unsurprisingly, Constance again emphasizes appearance when she refuses her son's attempt to calm her as she defends his claim to the throne.

What is surprising, however, is how much time she devotes to the appearance of a figure who is not actually there: 
If thou that bid'st me be content wert grim, Ugly and slanderous to thy mother's womb, Full of unpleasing blots and sightless stains, Lame, foolish, crooked, swart, prodigious, Patched with foul moles and eye-offending marks, I would not care, I then would be content; For then I should not love thee, no, nor thou Become thy great birth nor deserve a crown. But thou art fair, and at thy birth, dear boy, Nature and Fortune joined to make thee great.

Under the sign of a negating subjunctive — traversing the distance from 'if' and 'wert' to 'but' and 'art' - Constance conjures a visually repellent body to buttress her son's political claim. She offers a strange image of a body in outline, accomplished through an exceptionally long speech act, a veritable compendium of terms that are early modern cognates for physical difference. I think these two aspects are related, that the weirdly emphatic insistence in this counterfactual registers the constitutive incoherence of disability rhetoric and, in the process, demonstrates how much work it takes to arrive at 'fair' to describe the body of Arthur, who is actually onstage.

These terms range widely: 'slanderous' and 'prodigious' aspects of the imagined figure point to a monstrous birth; 'ugly' features with 'foul moles', 'blots', 'stains', and 'marks' express aesthetic disqualifications; 'swart' invokes a racialized judgment; 'foolish' maps intellectual deficiency; and 'lame' and 'crooked' limbs associate physical deformity with moral ills. She narrates these features in a prismatic array of physical and intellectual difference that works across early modern conceptual registers. The putative figure is 'eye-offending' and 'unpleasing', the very appearance of this body inviting disgust in the viewer. What is striking here is the lack of 'pity' or 'charity' that Constance understands as logical conclusion to the evidence of the fantasy she summons rhetorically: she 'would not care' about her son's advancement and 'should not love' him.

This anticipated effect, furthermore, is unconfined to the surface of the body; 'sightless stains' registers both the desire not to see this body and blemishes beyond the visible, gesturing to something inscrutably deeper while refusing the spectator's gaze. Such ambivalence expresses a moral understanding of deformity, an association of interior and exterior, but these details complicate the relation between inner and outer, between part and whole. The ekphrastic narration unfolds from feature to feature, but in effect troubles the coherence of the image. What does 
this body look like? The picture of physical difference shifts with the enumeration of each new attribute and the terms of disqualification never resolve into one thing. Subsequent beats of breathless asyndeton add up in 'Lame, foolish, crooked, swart, prodigious', a line that rushes from movement to intellect to appearance, further compounded in the very next line by the foregone details that 'patched' suggests. This disproportionate description finally balances four lines of repulsion against the single word 'fair'. The asymmetry evokes the privileged term of opposition - one that is clearly racialized in the early modern period - as an ideal. ${ }^{13}$ Here, however, 'fair' becomes yoked to terms that encompass the broadest range of physical and intellectual difference. This ideal, though, can only emerge from hyperbolic terms of unlikeness, the body that Constance conjures but is never actually presented.

The Arden editors of the play connect Constance's speech to Richard III, noting 'similar language describing abhorrent offspring' in Anne's curses directed at her husband's murderer, Richard Gloucester ('If ever he have child, abortive be it, / Prodigious, and untimely brought to light, / Whose ugly and unnatural aspect / May fright the hopeful mother at the view' [1.2.21-4]), and Margaret's curses directed to Richard himself ('Thou elvish-marked, abortive, rooting hog, / Thou that wast sealed in thy nativity / The slave of nature and the son of hell; / Thou slander of thy heavy mother's womb' $[1.3 .227-30]) .{ }^{14}$ Here is the signal difference between these texts, however: an actor embodies Richard Gloucester, and (in the second example) is even onstage, present for the address. The heightened terms - the metaphorical use and condensed narrative implicit in a term like 'elvish-marked' - come up against the body of an actor, and they may not quite stick, or their lack of fit might show. Richard himself, I have argued elsewhere, takes control of the narrative of his body at the beginning of the play that bears his name, claiming 'deformity' and inviting his audience to view the shape that fills out such a description. ${ }^{15}$ Constance's assertion, by contrast, works in opposition to the material presence of Arthur's body, evoking this threat against the body taken to be its ground and opposite. As a result, the cultural commonplaces implicit in the judgments she rehearses never demand mediation through the stubbornly corporeal body of an actor.

This example suggests that such displays of disability rhetoric allow the theatre to venture beyond the embodied form of the actor that is central to dramatic form, indulging in tropes that can never actually index a body. The play does so without an actual body against which the compacted densities of such adjectives might fail to succeed. We might understand Constance's piled clauses as a satirical rant, especially if the actor playing Arthur does not offer enough of a contrast 
to this marked body, an opportunity for rhetorical failure that is always present in the material embodiment of the character. (To follow this contrast, however, would produce difficulties for the tone of the scene, which begins and ends with lament.) This rhetorical event is an attempted fixing, an edifice of difference that marshals the force of disability discourse without ever showing the audience the body it conjures.

\section{Noting Deformed}

Constance's summoning of a hypothetical body unmarks the actual body of her son, by contrast, who is left with only 'fair' as his descriptor. My second example goes further afield, from a rhetorical device to an extended encounter with a character built out of nothing. This character, to return to Bérubé's formulation, is nothing but 'social relation': Deformed in 3.3 of Shakespeare's Much Ado About Nothing. When the Watchman overhears Borachio's remark, 'But seest thou not what a deformed thief this fashion is?' (3.3.119-20), he cannot help but break in with a comment: 'I know that Deformed. 'A has been a vile thief this seven year; 'a goes up and down like a gentleman: I remember his name' (121-3). ${ }^{16}$ Deformed is a character the Watchman makes up from a snatch of eavesdropping, a person associated with status transgression in the social hierarchy (he is merely like a gentleman). Perhaps his composition reflects the Watchman's xenophobic leap to conclusions, if the Watchman hears the 'de' in 'deformed' as the first part of a foreign name (like Don John). ${ }^{17}$ Perhaps the Watchman has literalized the overheard words even earlier, and, hearing 'sees thou not', assumes that Borachio is gesturing to someone he recognizes. The joke of Deformed is that the adjective has been turned into a noun, description taken for person. Modern editorial consensus supports this transformation by capitalizing the word, inviting the sense of a proper name.

Reading this scene as an allegory for critical interpretation of disability in the Renaissance, Jeffrey R. Wilson has recently argued that the watchmen both 'invent' Deformed and 'confuse ... the suggestion of something for the reality of that thing.' ${ }^{18}$ In this view, Deformed does not exist, is not materially present, and therefore is not real; Wilson extrapolates, finding the scene's parallel in the approaches of critics who consider disability as an identity category in the Renaissance. But Wilson's use of Deformed to critique the notion of disability identity as merely made up - leaving aside his appeal to stigma as the predominant category for early modern disability, which seems especially misguided in its dismissiveness of the important political implications of 'disability' - fails to comprehend the 
social insights that Deformed generates. What is more, the claim cannot account for his staying power in the play. As the play continues, Deformed keeps returning in assertions that he deserves the law's justice too. After Borachio's jubilant confession of the deceit he helped to perpetrate at Hero's window, the watch breaks in, and, as the Watchman charges the men, the first watchman adds, 'And one Deformed is one of them. I know him, 'a wears a lock' (3.3.162-3), and Seacoal insists 'You'll be made bring Deformed forth, I warrant you' (165-6). Deformed remains a point of contention, for Dogberry insists that he be taken into custody along with the others: 'And also the watch heard them talk of one Deformed' (5.1.297-8). This additive clause takes the spectre of punishment further by reintroducing a character who already, by the end of 3.3, seems like a worn-out joke but cannot be forgotten.

This extension of Deformed's presence proceeds from the character who continually prolongs conversational exchange through deformed words or malapropisms. Dogberry insists on Deformed's peculiar appearance ('they say he wears a key in his ear and a lock hanging by it' [298-9]), warning that he 'borrows money in God's name, the which he hath used so long and never paid, that now men grow hard-hearted and will lend nothing for God's sake' (299-302). Here 'nothing' makes Deformed the basis for a moralizing proverb about a social habit, exemplifying the problem of borrowing and lending. This passage turns Deformed into the inverse of Nobody, a character whose name and address rhetorically efface the material presence of his body on the stage. Nobody's body is filled out by an actor and troubles the pronoun's refusal of a name while Deformed exists in name only as a body entirely absent.

Deformed might be just another example in a theatrical funhouse of character except that Much Ado is all about 'noting' and 'nothing' and abounds with scrutiny of bodies. Commenting on Shakespeare's engagement with his source, Geoffrey Bullough suggests that Much Ado develops the idea of 'the importance of hearsay, the misinterpretation of things half-heard or seen', and the strangest omission from the source is that Much Ado does not stage, but only reports, the window scene in which Claudio watches the false show of Hero's infidelity. ${ }^{19}$ (Kenneth Branagh's popular film version of the play, by contrast, offers it as a visual flashback, converting the reported scene to voiceover effect. The trick of this choice is that access to the scene aligns us as viewers with Claudio, for we have exactly as much evidence as he to judge the figure in the window as Hero - and to turn against his conclusion and judge him when we, warned by the prospect of the plot, do not fall for the substitution.) Noting that 'Shakespeare does not present the scene in which the hero sees his "rival" climbing to his betrothed's 
window', Bullough speculates on his motive for the excision: 'Shakespeare refused to use it, I suspect, in order to draw attention to his major theme of hearsay and false report'. ${ }^{20}$ For Bullough, the choice to omit a crucial scene in the source creates a lacuna that works thematically.

I would suggest, however, that the omission of an expected scene and the introduction of an omitted character are two effects of the play's attention to the scrutiny of bodies more broadly. The play depends upon a belief that bodily evidence can be read for knowledge, one that goes far beyond the faked-Hero episode that substitutes one body for another. Deformed, that character assumed where no figure exists, is not merely a comic embellishment for the play or an imaginative excursion into rumour taken too seriously. Deformed is the logical extension of the play's faith in bodies to signify, and therefore, to be resignified, by others. Deformed is not a satirical departure from the play but the persistent reminder of the gap between bodily appearance and the scrutiny that makes meaning of it. After 3.3, which introduces Deformed and his 'fashion', the play only doubles down on the incoherence of knowledge premised upon noting. When Claudio rejects Hero, he will claim 'She's but a sign and semblance of her honour. / Behold how like a maid she blushes here!' (4.1.31-2) and 'Would you not swear, / All you that see her, that she were a maid, / By these exterior shows? But she is none' (378). The questions Claudio spits at Leonato gain their illogical force from bodily presence taken for fact of Hero's guilt: 'Leonato, stand I here? / Is this the Prince? Is this the Prince's brother? / Is this face Hero's? Are our eyes our own?' (69-71). When Leonato has fully embraced these accusations, he responds 'Why ever was thou lovely in my eyes?' (130), though the Friar's defense of Hero will rely on the logic of bodily sight-reading to make exactly the opposite claim about her innocence: 'I have marked / A thousand blushing apparitions / To start into her face' (158-60). Deformed decouples the form of the dramatic character from the form of the actor, and - especially crucial in a play so concerned with noting and visual verification - reminds us that the force of idealized abstractions can be so prescriptive that departures from form are possible to judge with no matter at all.

\section{Characterizing Disability}

Having moved from characterizing rhetoric to rhetoricized characters, I conclude this essay by considering how the keywords through which we read disability also serve as cues for actors. Encountering a keyword like 'lame' in the example with which this essay opened, perhaps the actor assumes a limp or a prosthesis such as 'Kentes woden leage', the stage property Philip Henslowe lists in his records. ${ }^{21}$ 
My implicit assumption in turning to the keywords with which I began is that by reading disability at the level of the character our critical practice of marking disability follows these invitations to the actor's work. When we think about disability, we think about the bodies described by such terms. And yet, the examples that I have just taken up demand that we notice the negotiation between literal and metaphorical, to consider how these terms point outward to social communities and trouble regimes of seeing. To explore this negotiation, I turn to one final example from Shakespeare's plays, The Comedy of Errors. This is a play given over to scrutinizing bodies from the outset. Appeals to appearance are on overdrive because they are the key mechanism of confusion that turns the Antipholuses and the Dromios into doubles of each other. For all of the jokes that turn on the impossibility of telling bodies apart — and there are many gags that spring from the situational comedy produced by the seeming interchangeability of two sets of brothers - this humour is deeply uneasy, and more recent scholarship on the play has helped us to see comic scenes as shot through with violence and abuse of power. From the beginning, bodily similarity, as opposed to difference, becomes a matter of urgency, and so the series of lines that appears late in the play describing Antipholus takes a surprising turn. Lamenting the behaviour of the man she believes to be her husband, Adriana exclaims:

He is deformed, crooked, old and sere,

Ill-faced, worse bodied, shapeless everywhere;

Vicious, ungentle, foolish, blunt, unkind,

Stigmatical in making, worse in mind.

Like Constance's apostrophe above, these are lines crammed with negative comment on bodily appearance. This asyndeton pileup of adjectives associates age ('old') and meanness ('vicious' and 'unkind') with more familiar terms of physical and intellectual difference. Here is 'crooked' and 'foolish' again; here is 'deformed'. Here, too, are less familiar but still suggestive terms like 'sere' (glossed as 'dry, withered') and 'shapeless' ('ugly, unshapely', definitions intensified by the global 'everywhere'). Kent Cartwright's editorial gloss links 'stigmatical in making' to Richard III, noting that Richard III is called 'foul stigmatic' in 2 Henry VI (5.1.215) and 'foul misshapen stigmatic' in 3 Henry VI (2.2.136). ${ }^{23}$

Yet where Constance enumerates variables of difference to describe a body that is only hypothetical, these lines have the effect of reorienting a character's appearance that we have already met. Marked but exceeding the limited condition of stigma, Adriana's act of description unsettles not just who Antipholus is (indeed, the editorial gloss reads, 'Adriana "re-invents" Ephesian Antipholus; perceptions 
of identity are becoming unstable') but also what he looks like. Adriana's language has been given to affective chagrin over appearance from her first scene in the play. Luciana calls this her 'self-harming jealousy' in prior scenes; Adriana denigrates her own appearance, worrying that Antipholus no longer regards her as beautiful and is unfaithful to her. When she earlier characterizes Antipholus as 'the ground / Of my defeatures' (2.1.98-9), she means the line to register his lack of love ('My decayed fair / A sunny look of his would soon repair' [99-100]), constructing her own appearance according to his affective response. In a play that so fully depends upon the notions that the estranged pairs of twins look identical, this suggestion that environment shapes appearances is startling. While Adriana's description of Antipholus in 4.2 might fit with her emphasis on how appearances decay or flourish according to the response of others, she changes her mind - despite the array of terms she has summoned — just a few lines later. Cartwright notes that 'Moments later, however, she equivocates — "I think him better than I say" - leaving her views unfixed'. ${ }^{24}$ While this comment sums up the unsettled relationship between thought and sight, the lines pose a practical question for a production that casts an actor (or two, if these transfer to the other Antipholus). Are the epithets description or projection? Cutting across a metaphorical interpretation, they represent a possible acting choice if these lines are taken retrospectively to characterize Antipholus, or they demonstrate the power of construction if Adriana summons a version of Antipholus that does not exist alongside the shape that we have been seeing.

More broadly, these examples ask us to account for the social effects of such descriptions that push against the bodies present on the stage. In the strangely extended discursive episodes such as those I have examined here, disability rhetoric functions as a kind of exoskeleton, a set of ideas about disability that limn a perfect negative form, or deformity, of concept. The prevalence of disability rhetoric employed to negative ends in early modern drama deserves critical attention that considers how the use of such rhetoric routinely metaphorizes disability so far as to sever the connection from a body. Never literalized, these examples ask us to contend with concepts of disability as a kind of abstraction far beyond a disability metaphor. They expose the metaphorical operations of a disability rhetoric that relies upon, and perhaps can only flourish in the condition of, being detached from a body. 


\section{Notes}

I am grateful to Susan Anderson; Katherine Hunt, Dianne Mitchell, and participants in the 'Literary Form After Matter' conference at Queens College, Oxford; and the anonymous reviewer for Early Theatre for their thoughtful and perceptive responses.

1 All quotations that follow are associated with search for 'lame' and quoted by act, scene, and line number as they appear on Eric M. Johnson, Open Source Shakespeare, MA thesis (George Mason University, 2003), http://www.opensourceshakespeare. org/search/search-results.php?link=con\&works[] =*\&keyword1=lame\&sortby=Work Name\&pleasewait $=1 \& \mathrm{msg}=\mathrm{S}$

2 See especially Elizabeth B. Bearden, Monstrous Kinds: Body, Space, and Narrative in Renaissance Representations of Disability (Ann Arbor, 2019), 1-32, https://doi. org/10.3998/mpub.10014355, and Kevin Stagg, 'Representing Physical Difference: The Materiality of the Monstrous', in Social Histories of Deformity and Disability, ed. David M. Turner and Kevin Stagg (Abingdon, 2006), 19-38, https://doi. org/10.4324/9780203008522.

3 See Rosemarie Garland-Thomson, Extraordinary Bodies: Figuring Physical Disability in American Culture and Literature (New York, 1997).

4 All quotations that follow are associated with a search for 'monstrous' and quoted by act, scene, and line number as they appear on Johnson, OpenSource Shakespeare.

5 Katherine Schaap Williams, "More Legs Than Nature Gave Thee”: Performing the Cripple in The Fair Maid of the Exchange', English Literary History 82.2 (2015), 491-519, https://doi.org/10.1353/elh.2015.0019.

6 Lindsey Row-Heyveld, Dissembling Disability in Early Modern English Drama (New York, 2018), 2, https://doi.org/10.1007/978-3-319-92135-8.

7 Genevieve Love, Early Modern Theatre and the Figure of Disability (London, 2018), 7.

8 David T. Mitchell and Sharon L. Snyder, Narrative Prosthesis: Disability and the Dependencies of Discourse (Ann Arbor, 2000), esp. 47-64, https://doi.org/10.3998/ mpub.11523.

9 See Jay Timothy Dolmage, Disability Rhetoric (Syracuse, 2015) and James Berger, The Disarticulate: Language, Disability, and the Narratives of Modernity (New York, 2014), https://doi.org/10.18574/nyu/9780814708460.001.0001.

10 Allison P. Hobgood and David Houston Wood, 'Ethical Staring: Disabling the English Renaissance', in Recovering Disability in Early Modern England, ed. Allison P. Hobgood and David Houston Wood (Columbus, 2013), 2.

11 Michael Bérubé, The Secret Life of Stories (New York, 2016), 19, 25. 
12 Quotations reference William Shakespeare, King John, Arden Third Series, ed. Jesse M. Lander and J.J.M. Tobin (London, 2018).

13 On 'fair' see Kim F. Hall, Things of Darkness: Economies of Race and Gender in Early Modern England (Ithaca, 1995), especially chap. 2.

14 King John, ed. Lander and Tobin, n 3.1.44-7; they quote, as I do here, from King Richard III, Arden Third Series, ed. James Siemon (London, 2009).

15 Katherine Schaap Williams, 'Performing Disability and Theorizing Deformity, English Studies 94.7 (2013), 757-72, https://doi.org/10.1080/0013838x.2013.840125; a revised and expanded version of this argument appears in Katherine Schaap Williams, Unfixable Forms: Disability, Performance, and the Early Modern English Theater (forthcoming from Cornell University Press).

16 Quotations reference William Shakespeare, Much Ado About Nothing, Arden Third Series, ed. Claire McEachern (London, 2015).

17 I owe this insight to Thomas Ward.

18 Jeffrey R. Wilson, 'The Trouble with Disability in Shakespeare Studies', Disability Studies Quarterly 37.2 (2017), n.p., https://doi.org/10.18061/dsq.v37i2.5430. Critiquing 'those arguing for the existence of "disabled" as an operational identity category in the Renaissance', he writes, 'the danger is that they have invented the reality of "disabled" in the Renaissance just as Shakespeare's characters invented the reality of Deformed'.

19 Geoffrey Bullough, ed. Narrative and Dramatic Sources of Shakespeare (London, 1964), 2.75, https://doi.org/10.4324/9780203439531.

20 Ibid., 2.76.

21 See Vin Nardizzi, 'The Wooden Matter of Human Bodies: Prosthesis and Stump in A Larum for London', in The Indistinct Human in Renaissance Literature, ed. Jean E. Feerick and Vin Nardizzi (New York, 2012), 121, https://doi. org/10.1057/9781137015693 8. See also Love, Figure of Disability, 69-102.

22 William Shakespeare, The Comedy of Errors, Arden Third Series, ed. Kent Cartwright (London, 2016), 3.

23 Ibid., n 4.2.22. Compare Patricia Akhimie's reading of somatic markers in The Comedy of Errors in Shakespeare and the Cultivation of Difference: Race and Conduct in the Early Modern World (New York, 2018).

24 Cartwright, 'Introduction', Comedy of Errors, 23. 
